\title{
MODIFIKASI MODEL PROPAGASI ERICSSON JARINGAN LTE-1800 MHz PADA DAERAH LEPAS PANTAI DENGAN MENGGUNAKAN LEAST SQUARE METHOD
}

\author{
Ade Yuda Wahyu Romadona ${ }^{1 *}$, Bengawan Alfaresi ${ }^{2}$,dan Feby Ardianto ${ }^{3}$ \\ 1,2,3Program Studi Teknik Elektro, Fakultas Teknik, Universitas Muhammadiyah Palembang \\ *Corresponding author, e-mail: adeyudha78@gmail.com
}

\begin{abstract}
Abstrak - Jaringan 4G memiliki keunggulan pada akses data dengan kecepatan yang lebih tinggi dibandingkan dengan pendahulunya yaitu $3 \mathrm{G}$. Tujuan dari penulisan ini adalah untuk mengetahui fluktuasi sinyal LTE-1800 MHz pada daerah Lepas Pantai kemudian melakukan Memodifikasi pemodelan propagasi Ericsson untuk mendapatkan hasil dengan kondisi yang sebenarnya (real) dan akurat. Serta melakukan perbandingan hasil perhitungan dari pemodelan eksisting Propagasi Ericsson dan perbandingan dari hasil modifikasi pemodelan yang di dapat. Metode yang digunakan pada penelitian ini ada empat tahapan yaitu tahapan 1). penentuan data awal, 2). alat dan bahan, 3). pengelompokan data dan 4). perhitungan pathloss. Penelitian dilakukan di daerah pesisir lepas pantai tepanya di kecamatan Panjang kabupaten Bandar Lampung. Pengujian kualitas jaringan 4G-LTE di daerah pesisir lepas pantai dilakukan dengan cara mengukur beberapa parameter penting yang berpengaruh seperti RSRP(Reference Signal Recived Power). Keseluruhan aktifitas pengukuran dikerjakan dengan menggunakan perangkat software Probe by wawe. hasil analisa pathloss sebelum dimodifikasi diperoleh nilai $173.5986043 \mathrm{~dB}$ dari hasil pemodelan sedangkan hasil setelah dimodifikasi mendapatkan hasil yang akurat yaitu $16.48853263 \mathrm{~dB}$ dalam perhitungan ini menggunakan model propagasi ericsson..
\end{abstract}

Kata Kunci : Jaringan 4G-LTE, ericcson model, Propagasi

\begin{abstract}
The 4G network has the advantage of accessing data at a higher speed compared to its predecessor, namely $3 \mathrm{G}$. The purpose of this is to see the fluctuation of LTE-1800 MHz signal in the offshore area then modify the Ericsson propagation modeling to get the results with real conditions (real) and accurate. As well as making comparisons of calculation results from existing Ericsson Propagation modeling and comparisons of the results of modifying modeling that can. The method used in this research is four stages: 1). determination of initial data, 2). tools and materials, 3). data grouping and 4). pathloss calculation. The research was conducted in a coastal area off the shore in Panjang district, Bandar Lampung district. Testing the quality of the 4G-LTE network in offshore coastal areas is carried out by measuring several important influencing parameters such as RSRP (Reference Signal Recived Power). All activities are carried out using software devices. Probe by wawe. Analysis of the results before the value $173.5986043 \mathrm{~dB}$ obtained from the modeling results from the accurate results of $16.48853263 \mathrm{~dB}$ in this calculation using the Ericsson propagation model.
\end{abstract}

Keywords : 4G-LTE network, ericcson model, propagation

\section{PENDAHULUAN}

Dewasa ini perkembangan teknologi telekomunikasi mengalami kemajuan yang sangat pesat terutama pada bidang telekomunikasi nirkabel (wireless) dalam menunjang teknologi informasi dan media internet. Telekomunikasi pada saat ini telah menjadi kebutuhan seluruh masyarakat Indonesia. Kebutuhan pelanggan untuk layanan multimedia broadband dengan kecepatan akses yang lebih cepat terus meningkat [1]. Pada generasi pertama atau disebut dengan 1G merupakan teknologi handphone pertama yang dikenalkan pada era 80-an da60n masih menggunakan sistem analog. 
Teknik komunikasi yang disebut frequency division multiple acces (FDMA) [2]. bukan tidak mungkin layanan 3G yang saat ini sudah tidak memenuhi harapan pelanggan. Teknologi LTE (Long Term Evolution) diharapkan dapat menjadi solusi layanan yang dapat terintegrasi baik layanan eksisting maupun layanan masa depan. Dengan adanya teknologi generasi keempat ini diharapkan bisa menunjang teknologi informasi dan media internet karena sudah menjadi kebutuhan di masyarakat [3].

Propagasi gelombang radio yang merupakan proses perambatan gelombang radio dari pemancar ke penerima. Transmisi sinyal dengan media nirkabel yang memerlukan antena untuk meradiasikan sinyal ke udara dalam bentuk gelombang elektromagnetik [4].

Untuk memprediksi pathloss, para insinyur merencanakan jaringan dengan meggunakan model propagasi salah satunya adalah model Ericsson. Metode model ericsson ini adalah hasil modifikasi dari model okumura hata dengan mengubah parameter propagasi yang akhirnya mengarah pada model ericsson. Insinyur jaringan menggunakan perangkat lunak untuk mengembangkan model ini [5].

Pada penelitian ini akan diteliti mengenai bagaimana memodifikasi model propagasi. Menggunakan model ericsson pada jaringan 4G LTE-1800 MHz pada pada daerah lepas pantai dengan menggunakan metode least square dikecamatan Panjang ,kabupaten Bandar Lampung. Penelitian ini akan mengukur kuat sinyal menggunakan software probe dan untuk menghasilkan akurasi pemodelan propagasi yang akurat sesuai dengan karakteristik dari wilayah pesisir lepas pantai. Untuk perhitungan dan penyajian datanya dilakukan menggunakan microsoft excel.

\section{TINJAUAN PUSTAKA}

\section{Path Loss}

Path loss adalah loss yang terjadi ketika data/sinyal melewati media udara dari antenna ke penerima dalam jarak tertentu. Path loss dapat timbul disebabkan oleh banyak faktor, seperti kontur tanah, lingkungan yang berbeda, medium propagasi (udara yang kering atau lembab), jarak antara antenna pemancar dengan penerima, lokasi dan tinggi antenna [6], [7].

\section{Drive test}

Drive test adalah kegiatan mengumpulkan informasi dari kualitas sinyal dalam suatu jaringan yang bertujuan untuk meningkatkan kualitas dari jaringan itu sendiri [8]. 


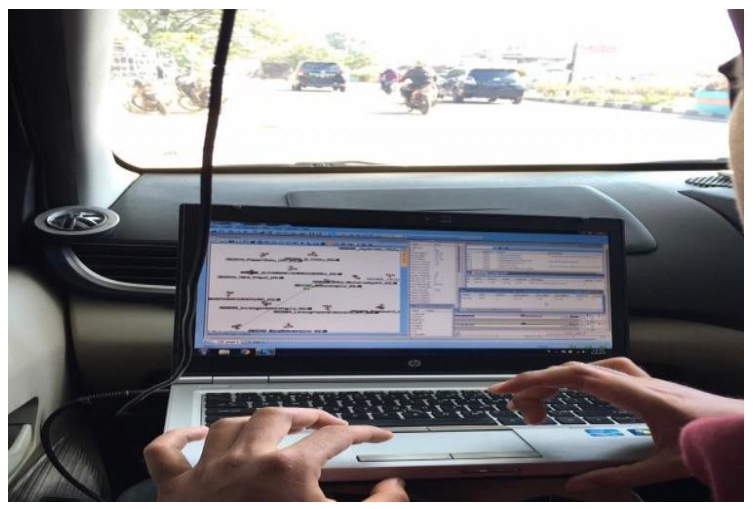

1. Peralatan Pengukur Uji Drive

Peralatan yang digunakan pada saat drive test yaitu terdiri dari laptop HP, Samsung S5 \& kabel data, dan GPS. Pengukuran menggunakan software Genex probe by wawe. Dalam hal ini penelitian pengambilan sample dilakukan menggunakan metode drive test dilokasi yang telah ditentukan dan rutenya sesuai dengan tujuan dari penelitian ini.

\section{Pemodelan Propagasi Erricsson}

Pada penelitian ini menggunakn Model Erricsson sebagai pemodelan existingnya. Untuk memprediksi path loss, para insinyur merencanakan jaringan untuk digunakan pada perangkat lunak yang disediakan oleh perusahaan Ericsson disebut model Ericsson. Metode model ericsson ini adalah hasil modifikasi dari model okumura hata dengan mengubah parameter propagasi yang akhirnya mengarah pada model ericsson. Insinyur jaringan menggunakan perangkat lunak untuk mengembangkan model ini. Dalam hal ini persamaannya adalah sebagai berikut [5];

Dengan persamaan ;

$$
L=a_{0}+a_{1} \log (d)+a_{2} \log \left(h_{b}\right)+a_{3} \log \left(h_{b}\right) \log (d)-3.2\left(\log \left(11.75 h_{r}\right)^{2}\right)+g(f)
$$

Dimana $g(f)$ adalah definisi dari ;

$$
g(f)=44.49 \log (f)-4.78(\log (f))^{2}
$$

Dengan ;

$\mathrm{f}=$ frekuensi $(\mathrm{MHz})$

$\mathrm{h}_{\mathrm{b}}=$ tinggi antenna transmisi $(\mathrm{m})$

$\mathrm{h}_{\mathrm{r}}=$ jarak ketinggian antenna penerima $(\mathrm{m})$

Nilai default dari parameter ini $\left(\mathrm{a}_{0}\right),\left(\mathrm{a}_{1},\right),\left(\mathrm{a}_{2}\right)$, , dan $\left.\mathrm{a}_{3}\right)$ 
Tabel 1 Fungsi-fungsi Network Element pada LTE

\begin{tabular}{|c|c|c|c|c|}
\hline Lingkungan & $a_{0}$ & $a_{1}$ & $a_{2}$ & $a_{3}$ \\
\hline Kota & 36.2 & 30.2 & 12 & 0.1 \\
\hline $\begin{array}{c}\text { Pinggiran } \\
\text { kota }\end{array}$ & 43.2 & 68.93 & 12 & 0.1 \\
\hline pedesaan & 45.2 & 100.6 & 12 & 0.1 \\
\hline
\end{tabular}

\section{Modifikasi model propagasi}

Penambahan persamaan regresi linear pada persamaan Ericson model untuk melakukan modifikasi yang mana menggunakan persamaan sebagai berikut [9] [10];

$$
Y=a+b \times \log (d)
$$

Dimana $\alpha$ adalah konstan, $b$ adalah koefisien regresi (kemiringan), dan $d$ adalah jarak . Nilai $a$ dan $b$ dapat ditentukan sebagai berikut ;

$$
a=\frac{(\Sigma y)\left(\sum x^{2}\right)-\left(\sum x\right)\left(\sum x y\right)}{n\left(\sum x^{2}\right)-\left(\sum x\right)^{2}}
$$

$$
b=\frac{n\left(\sum x y\right)-\left(\sum x\right)\left(\sum y\right)}{n\left(\sum x^{2}\right)-\left(\sum x\right)^{2}}
$$

Dimana $\Delta L$ adalah selisih antara nilai pathloss dari pengukuran drive test dan pemodelan.

\section{Evaluasi Hasil Pemodelan}

Pada evaluasi hasil pemodelan kali ini dilakukan untuk mengukur tingkat akurasi dari hasil perkiraan suatu pemodelan. Dengan cara mengurangkan hasil perhitungan dengan hasil pengukuran dibagi dengan jumlah data, kemudian di akarkan. Berikut hasil perhitungan menggunakan rumus Root mean Squared Error (RSME) [10] :

$$
R S M E=\sqrt{\frac{\sum(\text { PLMeas }- \text { PLModel })^{2}}{n}}
$$

dimana:

$n=$ banyaknya sample data.

$P L \_m e a s=$ nilai yang diperoleh dengan mengukur perangkat.

$P L \_$model $=$nilai yang diperoleh menggunakan persamaan . 


\section{METODE PENELITIAN}

Pada penelitian ini melalui beberapa tahapan penelitian yaitu tahap pertama analisa data awal yang merupakan studi literatur pada jurnal maupun buku yang berhubungan dengan propagasi gelombang radio. Kemudian tahap kedua persiapan alat dan bahan yaitu berupa hardware (laptop) maupun software (Genex Probe By Wawe dan Microsoft Excel). Tahapan ketiga proses pengelompokkan data dan tahapan keempat yaitu perhitungan dan memodifikasi hasil dari perhitungan tersebut dan melakukan analisa terhadap hasil simulasi.

\section{HASIL DAN PEMBAHASAN}

\section{A.Hasil Perhitungan Data Pengukuran Pada Loss Terhadap Jarak}

Sebelum dapat memodelkan nilai Loss (L) terhadap Jarak (D), nilai ini harus melalui tahapan pengolahan data. Data-data yang didapatkan dari hasil pengukuran kemudian diolah sedemikian rupa dengan menggunakan mapinfo, kemudian dipindahkan ke dalamMicrosoft Excel. Untuk memudahkan menganalisis, maka data diplot kedalam grafik menggunakan microsoft excel. Gambar 2 menampilkan grafik hasil pengukuran dilapangan.

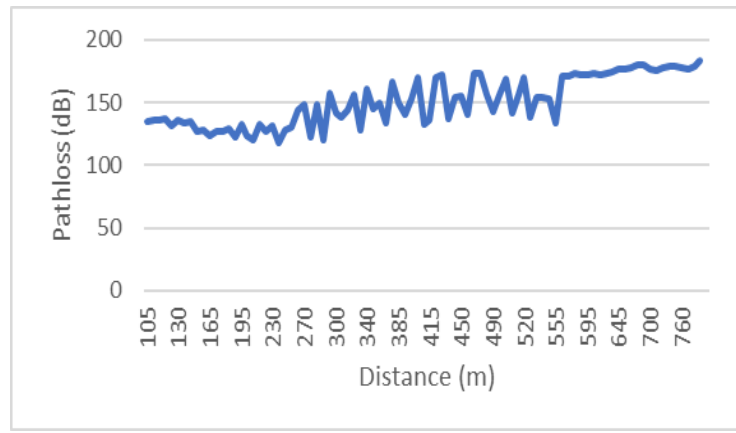

Gambar 2 Grafik Pengukuran

Dari gambar 2 grafik pengukuran dilihat adanya penurunan level daya terima sinyal pada daerah lepas pantai. Untuk pengukuran dilakukan pada jarak 105m hingga 795m, dan didapatkan loss sinyal tertinggi jarak 555m hingga 795m Penurunan daya terima ini disebabkan karena kondisi lingkungan yang berupa adanya perbukitan dengan ketinggian yang melebihi BTS. Terlihat bahwa nilai pathloss yang cukup tinggi apabila jarak antara BTS dengan mobile station semakin jauh.

\section{B.Hasil Perhitungan pemodelan}

Gambar 3 merupakan hasil pengukuran dilapangan dengan hasil perhitungan menggunakan microsoft excel.

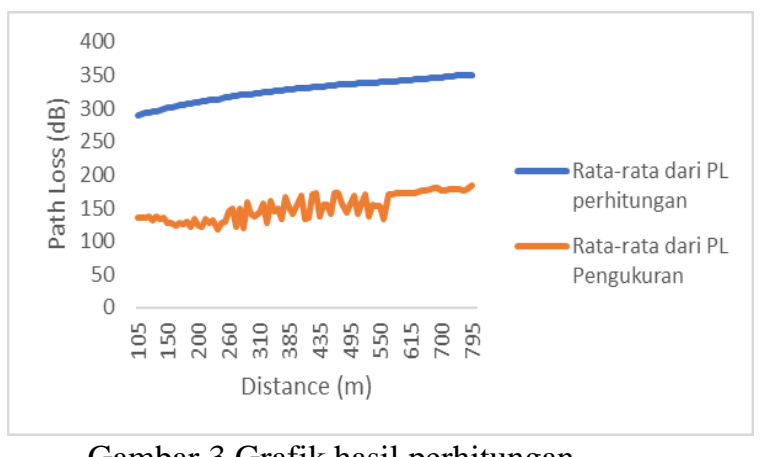

Gambar 3 Grafik hasil perhitungan 
Dari grafik 3 ini terlihat bahwa jika hanya menggunakan pemodelan ericsson saja hasilnya belum bisa mendekati hasil real dari pengukuran dilapangan. Maka dari itu dilakukan modifikasi untuk mendapatkan hasil yang mendekati real pengukuran dilapangan.

\section{Modifikasi Pemodelan Propagasi}

Untuk melakukan modifikasi pemodelan ini dengan menambahkan persamaan Regresi Linear. Untuk melakukan modifikasi, langkah pertama yang dilakukan adalah mencari selisih nilai antar path loss (PL) hasil pengukuran dengan path loss (PL) hasil perhitungan. Dari nilai selisih tersebut dicari dengan menggunakan model regresi linier.

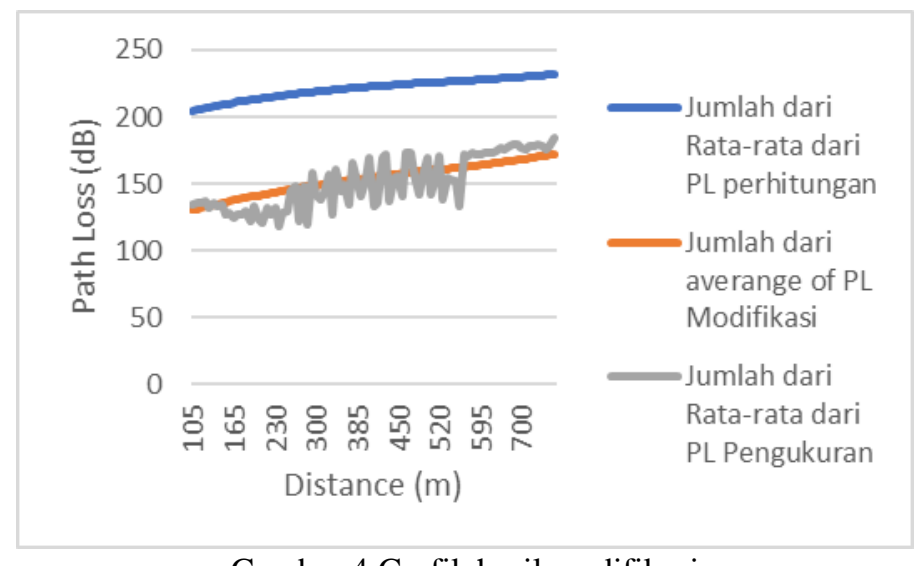

Gambar 4 Grafik hasil modifikasi

Gambar 4 menunjukkan hasil dari pathloss yang dihasilkan oleh model ericsson. Pada hasil perhitungan sebelum dimodifikasi terlihat hasilnya cukup jauh namun ketika sudah dimodifikasi hasilnya menunjukkan mendekati real seperti pada saat pengukuran dilapangan.

\section{Evaluasi Hasil Pemodelan}

Pada evaluasi hasil pemodelan ini dilakukan dengan menggunakan persamaan root mean squared error (RSME). Dari perhitungan tersebut didapat hasil dengan tingkat akurasi yang signifikan yaitu $16.48853263 \mathrm{~dB}$, yang mana sebelum adanya penambahan persamaan regresi linear ini yaitu $173.5986043 \mathrm{~dB}$. Dengan menggunakan pemodelan baru kita bisa mendapatkan hasil yang lebih bagus dan akurat mendekati hasil dari pengukuran dilapangan.

\section{KESIMPULAN}

1.Pada pemodelan ini didapati hasil bahwa semakin jauh daya terima maka semakin kecil.

2.Pada modifikasi model ericsson dengan menambahkan persamaan regresi linear menghasilkan tingkat akurasi yang mendekati kondisi yang real seperti hasil pengukuran, yang semula hasilnya $289.0986 \mathrm{~dB}$ dengan adanya modifikasi maka hasilnya menjadi $134.588 \mathrm{~dB}$ artinya dengan dilakukannya modifikasi ini mendapatkan hasil yang signifikan.

3.Jadi bisa disimpulkan setelah dilakukan perhitungan maka dapat dibandingkan dengan hasil pengukuran menggunakan persamaan RMSE yang bertujuan untuk mengetahui tingkat keakuratan yang mana hasil sebelum dimodifikasi yaitu $173.5986043 \mathrm{~dB}$ dan setelah dimodifikasi hasilnya 
adalah 16.48853263 dB. Artinya dengan adanya modifikasi ini didapatkan perubahan yang mendekati hasil sebenarnya yang ada dilapangan..

\section{DAFTAR PUSTAKA}

[1] D. Saputro, "Analisis Perencanaan Jaringan LTE di Pita Frekuensi 3500 MHz dengan Mode TDD dan FDD," Telekomunikasi dan Komputer, vol. 7, pp. 35-60, 2016.

[2] F. K. Utami dan H. Alfin, "Perencanaan Femtocell 4G LTE 1800mhz Studi Kasus Gedung Baru ST3 Telkom Purwokerto," 2016.

[3] W. Pradono, "Dampak Sosial Ekonomi dan Peran Pemerintah Daerah dalam Perkembangan Teknologi Pitalebar di Indonesia," Buletin Pos dan Telekomunikasi, vol. 14, pp. 131-146, 2016.

[4] M. Marzuki dan B. Irawan, "Analisa Propagasi Gelombang Continuous Wave Pada Radio Amatir di Frequency 21 MHz," Telekomunikasi dan Komputer, vol. 7, pp. 213-236, Desember 2016.

[5] C. Emeruwa dan P. Iwuji, "Determination Of A Pathloss Model For Long Term Evolution (Lte) In Yenagoa," Engineering and Science, vol. 7, no. 10, pp. 38-44, 2018.

[6] I. Dewanti, A. Wahyudin dan A. Hikmaturrokhman, "Analisis Perbandingan Passive Repeater Back-To-Back," SENATEK 2017, pp. 1-8, 2017.

[7] F. Nasution, D. Faiza dan K. Budayawan, "Analisis Model Propagasi Komunikasi Bergerak Pada Sistem Gsm Di Pt. Xl Axita Padang," Vokasional Teknik Elektronika \& Informatika, pp. 11-21, Januari-Juni 2016.

[7] A. Fajar dan E. Devia, "Analisa Dan Optimalisasi Jaringan 4g Lte Dengan Metode Electrical Tilt Menggunakan Drivetest," JURNAL JIIFOR, vol. 1, pp. 78-87, 2017.

[9] F. R. Hariri, "Metode Least Square Untuk Prediksi Penjualan Sari Kedelai Rosi," SIMETRIS, vol. 7, pp. 731-736, November 2016.

[10] B. Alfaresi, T. Barlian, F. Ardianto dan M. Hurairah, "Path Loss Propagation Evaluation and Modelling based ECC-Model in Lowland Area on $1800 \mathrm{MHz}$," Journal of Robotics and Control (JRC), pp. 167-172, 2020. 